NASA Technical Memorandum 100808

\title{
Modeling of Some Coplanar Waveguide Discontinuities
}

\author{
(NASA-TH-1008C8) DODELIHG OF SCEE COPLAMAB \\ WAVEGUIDE DISCONTIUUITIES (BASA) $10 \mathrm{~g}$ \\ CSCL $20 \mathrm{~N}$
}

N88-17880

\section{G3/32 0124550}

Rainee N. Simons and George E. Ponchak

Lewis Research Center

Cleveland, Ohio

Prepared for the

IEEE MTT-S International

Microwave Symposium

New York, New York, May 25-27, 1988 


\section{ORIGINAL PAGE IS OF. POOR QUALITY.}

MODELING OF SOME COPLANAR WAVEGUIDE DISCONTINUITIES

Rainee N. Simons and George E. Ponchak

National Aeronautics and Space Administration Lewis Research Center

Cleveland, Ohio 44135

\section{ABSTRACT}

The paper presents lumped equivalent cir cuit models for several coplanar waveguide discontinuities such as an open circuit, a series gap, and a symmetric step, and their element values as a function of the discontinuity physical dimensions. The model element values are de-embedded from measured $\mathrm{S}$-parameters. The frequency dependence of the effective dielectric constant was measured and compared to computed values.

\section{INTRODUCTION}

A coplanar waveguide (CPW) on a dielectric substrate (1) consists of a center strip conductor with semi-infinite ground planes on either sides (Fig. 1). Coplanar waveguide offers several advantages over conventional microstrip line: it facilitates easy shunt as well as series mounting of active and passive devices, it eliminates the need for wrap-around and via-holes, and it has a low radiation loss. These, as well as several other advantages, make CPW ideally suited for microwave integrated circuit applications $(2,3)$. However, very little information is avallable in the literature on discontinuity models for $\mathrm{CPW}(4,5)$. This lack of sufficient discontinuity models for CPW has limited the extent of applications for CPW in microwave circuit design.

This paper presents for the very first time lumped element equivalent circuit models for various discontinuities, together with their element values as a function of the discontinuity physical dimensions. These element values are de-embedded from measured scattering parameters of the discontinuities. The discontinuities characterized in this paper are a series gap in the center conductor, a symmetric step in the center conductor, and an open circuit for two different center conductor widths.

The characteristic impedance for both geometries was $50 \Omega$. The frequency dependence of the effective dielectric constant, $\varepsilon$ (eff), was also measured and is compared to computed values from the $1 \mathrm{iterature.}$

\section{DE-EMBEDDING DISCONTINUITY SCATTERING PARAMETERS}

Precision CPW calibration standards such as open circuits, short circuits, and $50 \Omega$ matched loads for calibrating an automatic network analyzer (ANA) are currently not available. Consequently, a two-tier de-embedding technique which has been used successfully to characterize active devices such as GaAs MESFET's $(6,7)$ was used to characterize the CPW discontinuities. The two-tier de-embedding technique consists of calibrating the ANA using precision coaxial standards and then using the calibrated ANA to characterize the test fixture. A CPW circuit whose characteristics are known is placed in the test fixture during the fixture characterization. The CPW circuit consists of a uniform section of a $50 \Omega \mathrm{CPW}$ line terminated at both ends by a linearly tapered CPW line which provides impedance matching to a pair of coaxial connectors. Thus, the CPW linear tapers and the coaxlal connectors form a part of the test fixture and are characterized initially. The characterization is done by measuring the four s-parameters on an HP8510 ANA. The test fixture with a CPW circuit on 0.125 in. RT-5880 Duroid is shown in Fig. 2.

A mixed lumped-distributed equivalent circuit topology to model the fixture was developed by taking into consideration the physical nature of the test fixture and the CPW circuit. The coaxial connectors were represented by a section of a lossy transmission line consisting of lumped elements in series with a small section of a coaxial line. The tapered CPW section was modeled as a multiple section stepped impedance transformer. EEsof Touchstone's (8) model of CPW as a lossless transmission line whose propagation characteristics are described by Ghione and Naldi ( 9 ) was used throughout the modeling experiment.

The elements of the equivalent circuit were then optimized to match the measured 5 parameters using the EEsof Touchstone circuit analysis and optimization programs. The circuit model is shown in Fig. 3. Figure 4 shows the measured and modeled S11 and S21 characteristics for the test fixture and thru line. This model was then used to de-embed the discontinuity characteristics from the fixture characteristics. The measured return loss with the $50 \Omega \mathrm{CPW}$ circuit in place is better than $16 \mathrm{db}$ over the frequency range 0.045 to $18 \mathrm{GHz}$. However, for 
the purpose of de-embedding the discontinuity equivalent circuit parameters, a I GHz band centered at $6 \mathrm{GHz}$ was chosen.

\section{EFFECTIVE DIELECTRIC CONSTANT}

The $\varepsilon$ (eff) is determined from the physical length of a pair of series-gap coupled straight resonators which are terminated in a short circuit and the measured resonant frequencies as described in (10). Figures $5(a)$ and (b) show $\varepsilon$ (eff) for $50 \Omega \mathrm{CPW}$ with two different strip widths over the frequency range of 3 to $18 \mathrm{GHz}$. Also shown in Figs. 5(a) and (b) is e(eff) computed using the expressions in (1), (9), and (11). Good agreement is observed between the measured and computed results above $6 \mathrm{GHz}$. The $\varepsilon$ (eff) does not appear to be a strong function of the center strip width for CPW lines of the same impedance.

\section{CPW OPEN CIRCUIT}

A CPW open circuit is formed by ending the center strip a snort distance before the slot ends, thereby creating a gap, gl, as shown in Fig. 6 . An electric field exists at the open circuit between the terminated center strip and the surrounding ground conductor and hence gives rise to a capacitive reactance. This reactance is seen at a plane coincident with the open end of the center strip. Thus the apparent position of the open circuit is beyond the physical end of the center strip. The open circuit capacitance, $C o c$, is a parallel combination of the capacitance due to the fringing fields across the gap, $g l$, and those across the slot, $W$. The gap dependent capacitance varies proportionally as $1 / \mathrm{gl}$. The slot dependent capacitance is constant. Figure 7 presents the de-embedded open circuit capacitance, Coc, as obtained from the measured $S-$ parameters.

\section{SERIES GAP IN THE CENTER CONOUCTOR}

A series gap of length $g$ in the center conductor of a CPW is shown in Fig. 6. The gap is modeled as a lumped $\mathrm{Pi}$-network consisting of a coupling capacitance, $\mathrm{C} 2$, and two fringing capacitances, $\mathrm{Cl}$. Analogous to the open circuit, the capacitance across the gap, C2, decreases proportionally as $\mathrm{l} / \mathrm{g}$. The fringing capacitance, $\mathrm{Cl}$. increases from the CPW line capacitance for $g=0$ to the open circuit saturation capacitance for large $g$. Figure 8 shows the de-embedded capacitances obtained from the measured $S$-parameters as a function of the gap width $g$.

\section{STEP CHANGE IN THE WIDTH OF CENTER CONDUCTOR}

A step change in width of the center conductor of $\mathrm{CPW}$ is shown in Fig. 6. The step discontinuity perturbs the normal CPW electric and magnetic fields which give rise to additional reactances. These additional reactances are assumed to be lumped and located in the plane of the step discontinuity. The modeling experiments show that the reactances can be modeled as a shunt capacitance Cs. The influence of this capacitance is to effectively lengthen the lower impedance CPW line towards the higher impedance CPW line. Figure 9 shows $\mathrm{Cs}$ as a function of the normalized step width. As the normalized step change, S1/S2, increases, Cs approaches the open circuit saturation capacitance.

\section{DISCUSSIONS}

Although the results presented in this paper appear to be self consistent, a mention of the accuracy of the data is required. The two port circuit element models are more accurate than the one port circuit element models. This is because the two port models are based on all four $S$ parameters versus a single S-parameter for the one port models. Furthermore, the open circuit model is a function of the phase of sil only. Therefore, the open circuit de-embedded capacitance is sensi tive to phase errors. To minimize the phase errors, several precautions were taken. All measurements were made in the frequency range at which the measured propagation constant was close to that used by Touchstone. In addition, the line length from the open circuit to the transition was kept short to minimize the difference in electrical length between the measured and that used by Touchstone.

To take into account the errors intrinsic in printed circuit board fabrication, all line lengths were measured to a tenth of a mil. Even with these precautions, the error is believed to be 5 percent for the open circuit data. Further testing of a larger sample of circuits should yield more complete and accurate results.

\section{CONCLUSIONS}

The paper presents for the very first time lumped equivalent circuit models for the following CPW discontinuities: an open circuit, a series gap in the center conductor and, a symmetric step in the center conductor. The model element values are de-embedded from the measured 5 -parameters and presented as a function of the discontinuity physical dimensions. The measured frequency dependence of $\varepsilon$ (eff) is also compared to computed values and found to be in good agreement above $6 \mathrm{GHz}$.

\section{REFERENCES}

1. C.P. Wen, "Coplanar Waveguide, A Surface Strip Transmission Line Suitable For Nonreciprocal Gyromagnetic Device Applications," IEEE Trans. Microwave Theory Tech., vol. MTT-17, pp. 1087-1090, Dec. 1969.

2. R.E. Stegens and D.N. Alliss, "Coplanar Microwave Integrated Circuit for Integrated Subsystems," MSN Microwave Syst. News, vol. 17. pp. 84-96, Oct. 1987.

3. D. Neuf and S. Spohrer, "UItrasmall MIC Mixer Designed for ECM Applications, "MSN Microwave Syst. News, vol. 15, pp. 70-82, Oct. 1985.

4. K.C. Gupta, R. Garg, and R. Chadha, Computeraided Design of Microwave Circuits. Dedham: Artech house Inc., 1981, Chap. 6. 


\section{ORIGINAL PAGE IS OE POOR QUALITY}

5. R.K. Hoffmann, Handbook of microwave integrated circuits. Norwood: Artech House Inc., 1987, Chap. 13.

6. R. Lane, "De-embedding Device Scattering Parameters," Microwave J., vol. 27, pp. 149-156, Aug. 1984 .

7. G.E. Elmore and L.J. Salz, "Quality Microwave Measurement of Packaged Active Devices," Hewlett-Packard J., vol. 38, pp. 39-48, Feb. 1987.
8. EEsof Touchstone Reference manual, Version 1.5, EEsof Inc., Mar. 1987.

9. G. Ghione and C. Naldi. "Analytical Formulas for Coplanar Lines in Hybrid and Monolithic MICs," Electron. Lett., vol. 20, pp. 179-181, Feb. 1984 .

10. T.C. Edwards, Foundations for Microstrip Circuit Design. New York: John Wiley \& Sons, 1981. Chap. 7 .

11. R.N. Simons, "Suspended Coupled Slotline Using Double Layer Dielectric, "IEEE Trans. Microwave Theory Tech., vol. MTT-29, pp. 162-165, Feb. 1981 .

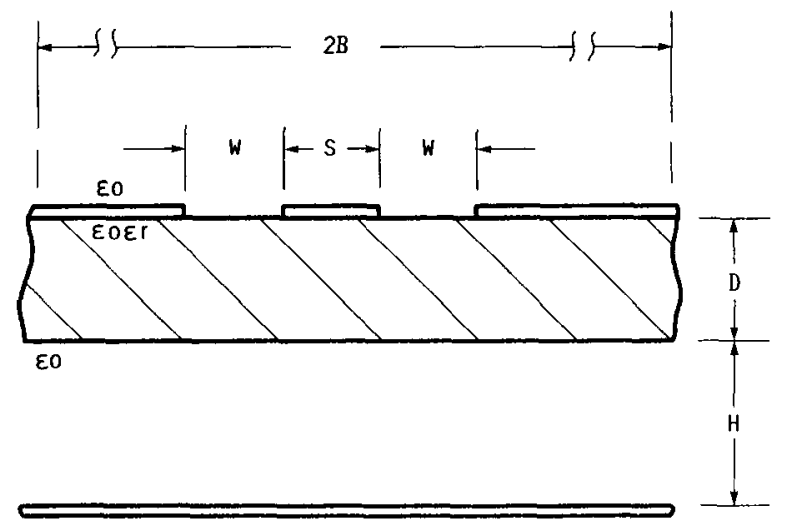

FIGURE 1. - CROSS-SECTION OF THE COPLANAR WAVEGUIDE IN THE TEST FIXTURE. 


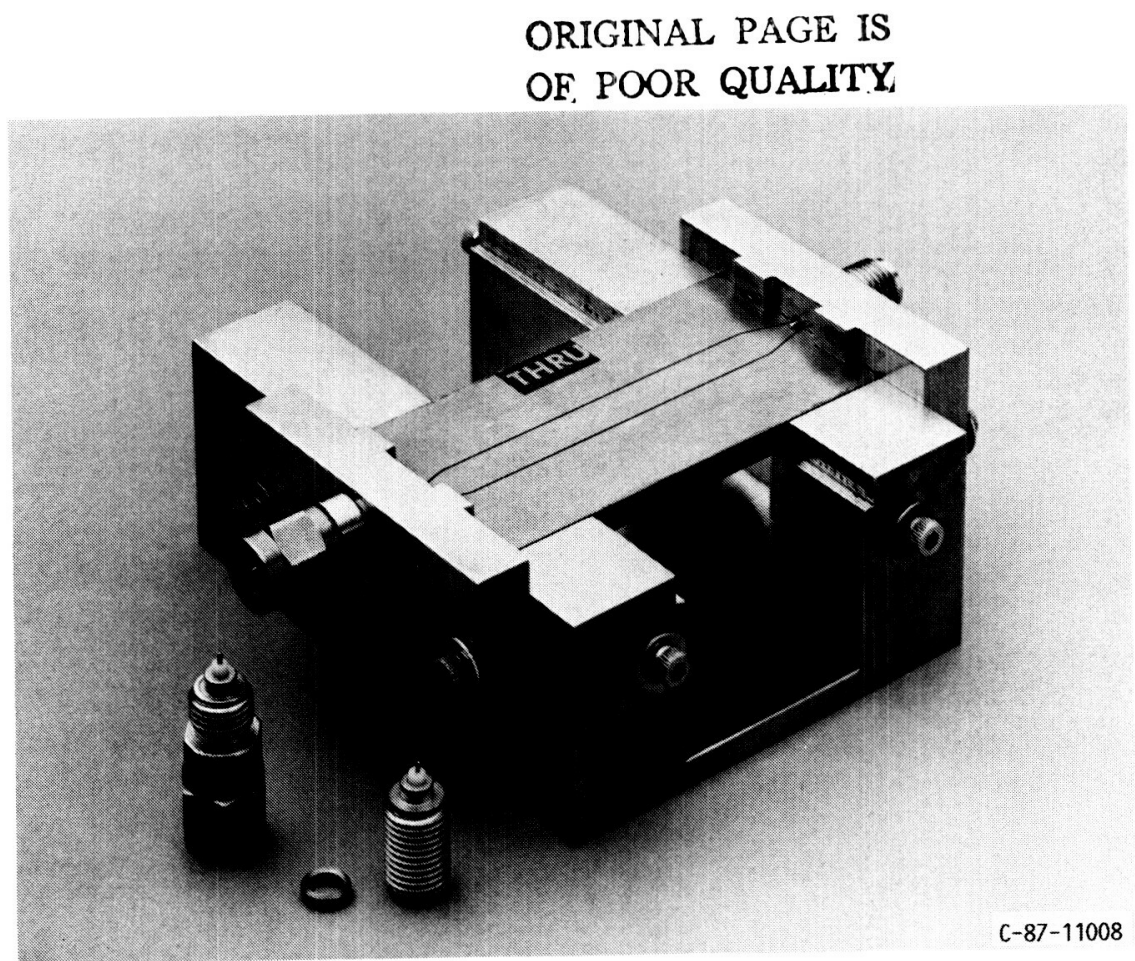

FIGURE 2. - TRANSITION BETWEEN A 50-OHM CPW AND COAXIAL CONNECTORS USING A LINEAR TAPER TRANSFORMER.

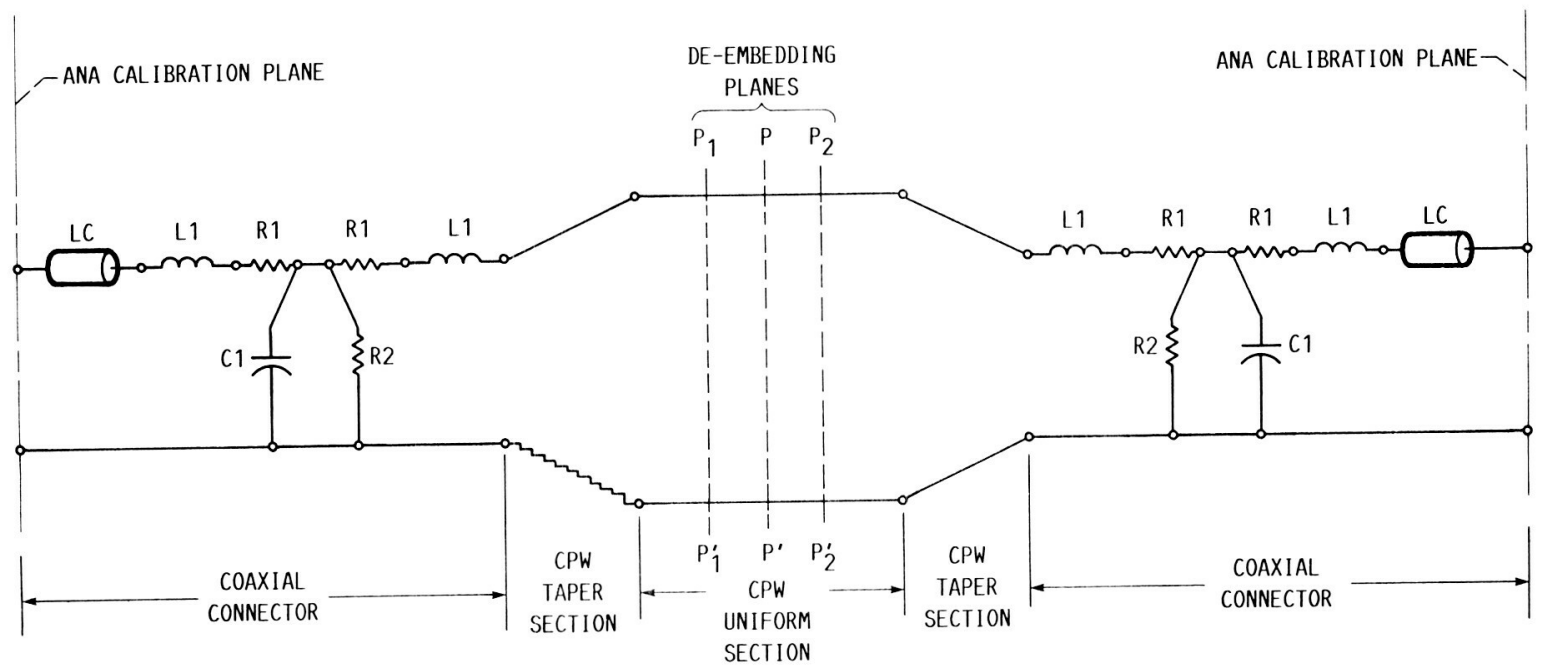

FigurE 3. - A LUMPED ELEMENT EQUIVALENT CIRCUIT MODEL OF THE TRANSITION BETWEEN THE 50-OHM CPW AND COAXIAL CONNECTOR. 


\section{ORIGINAL PAGE IS OF POOR QUALITY}

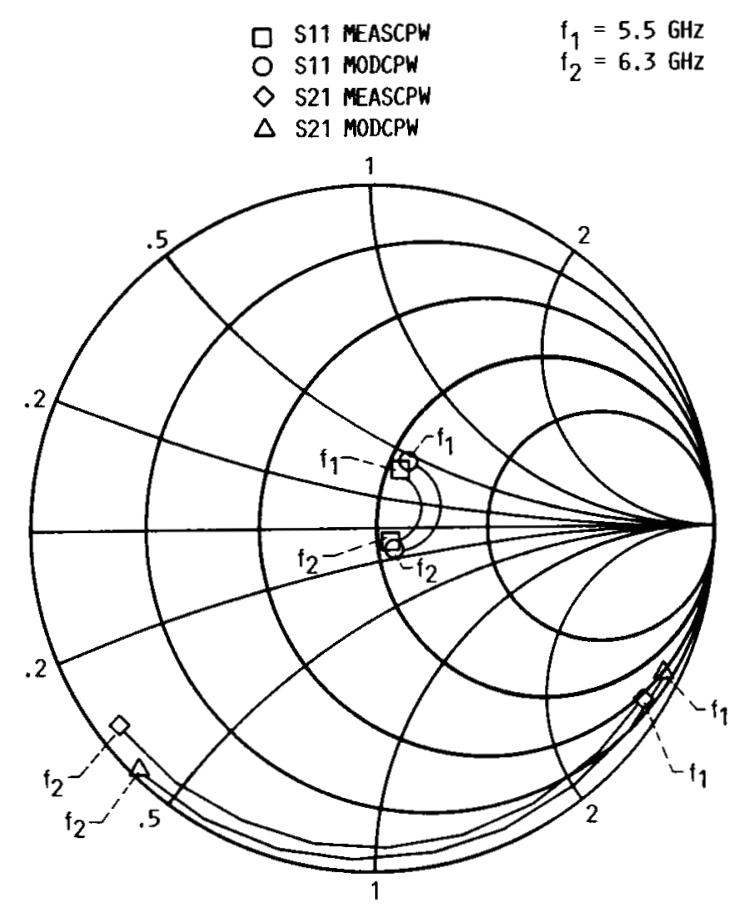

FIGURE 4. - MEASURED (MEASCPW) AND MODELED (MODCPW) S-PARAMETERS OF THE TRANSITION BETWEEN CPW AND COAXIAL CONNECTOR. 


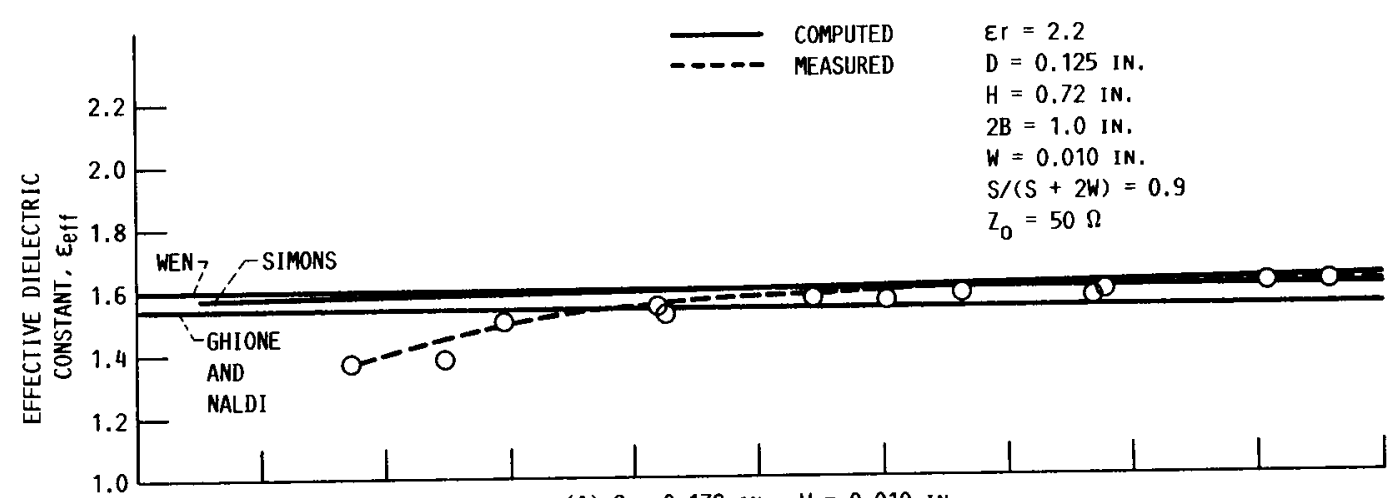

(A) $S=0.178 \mathrm{IN} ., W=0.010 \mathrm{IN}$.

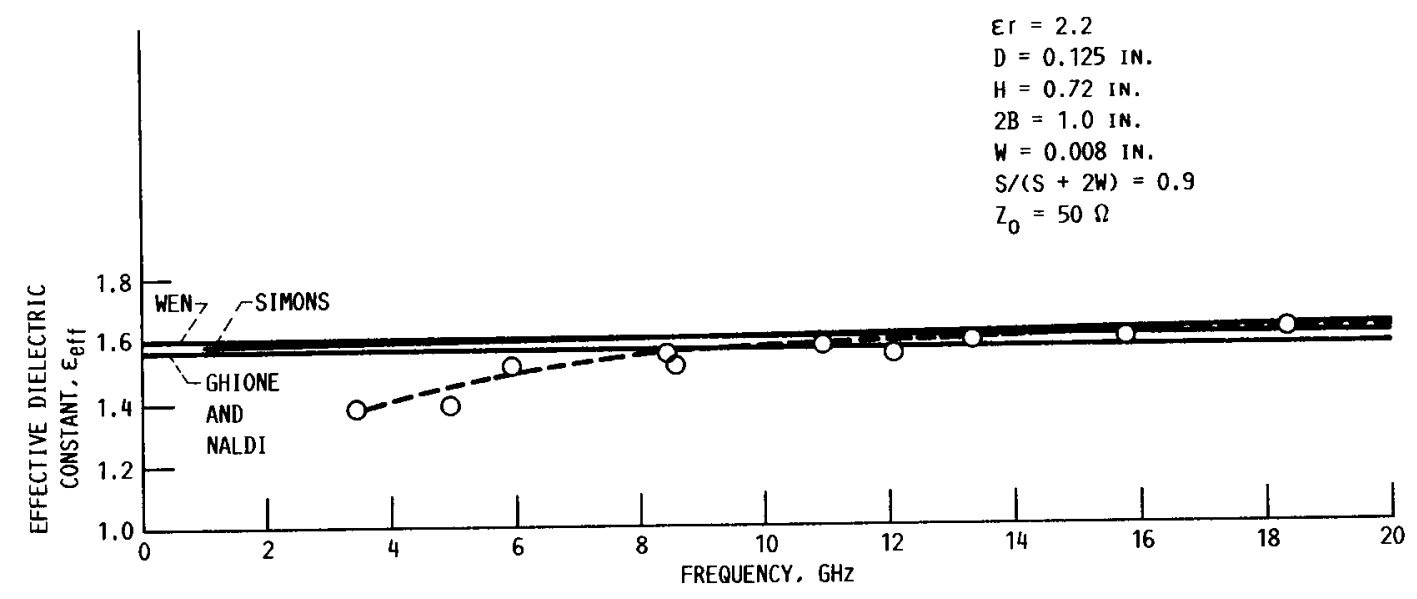

(B) $S=0.1454$ IN., $W=0.008$ IN.

FiguRE 5. - MEASURED AND COMPUTED EFFECTIVE DIELECTRIC CONSTANT OF CPW AS A FUNCTION OF FREQUENCY. 


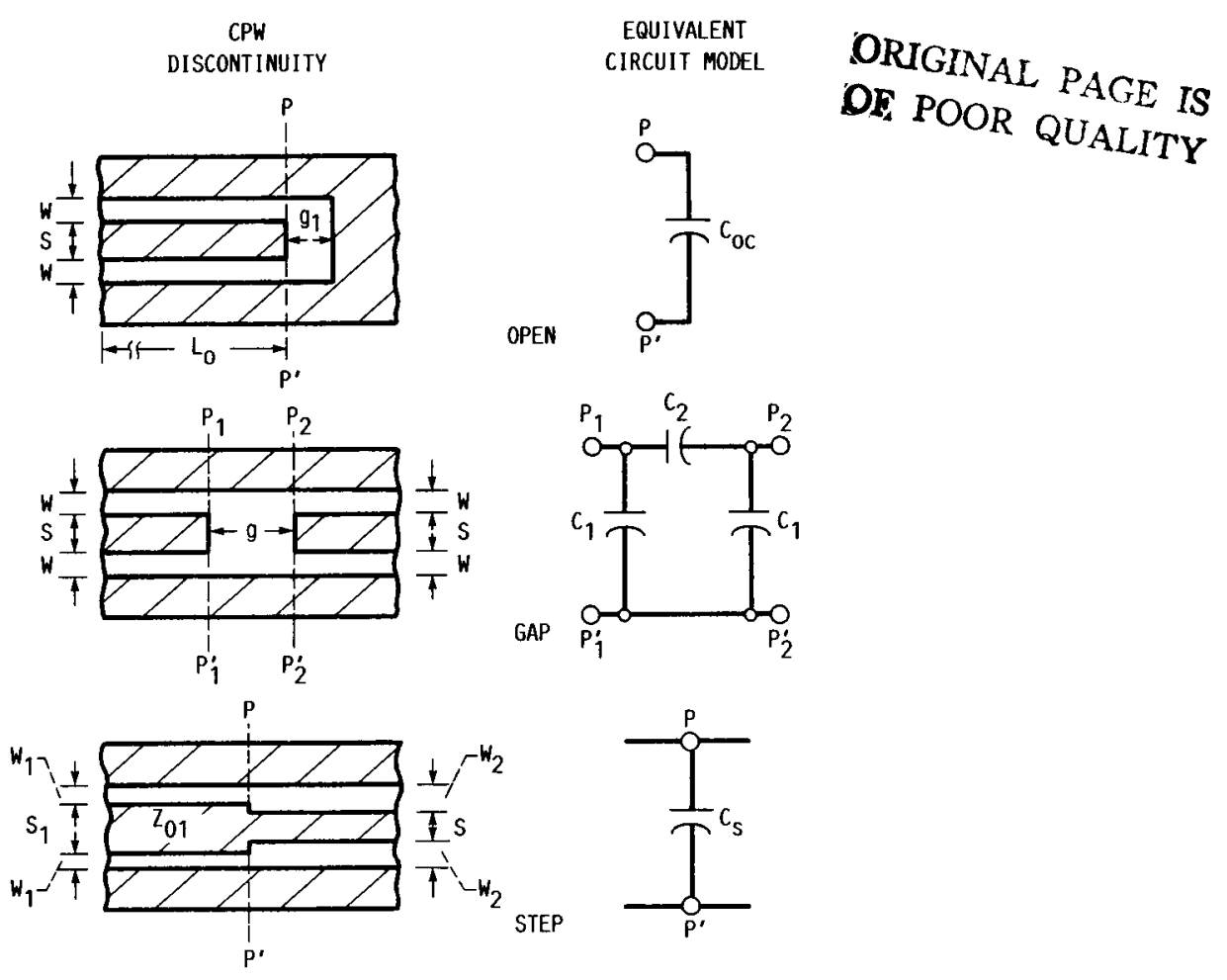

FIGURE 6. - COPLANAR WAVEGUIDE DISCONTINUITIES AND THEIR LUMPED ELEMENT EQUIVALENT CIRCUIT MODEL.

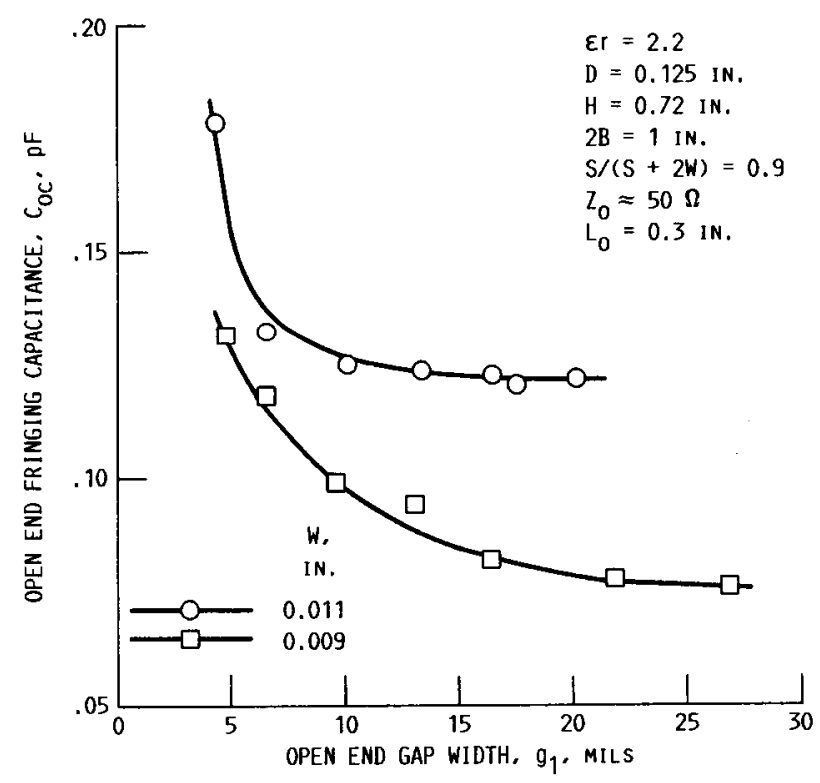

FIGURE 7. - DE-EMBEDDED LUMPED FRINGING CAPACITANCE FROM MEASURED SCATTERING PARAMETERS AS A FUNCTION OF THE OPEN END GAP WIDTH. 

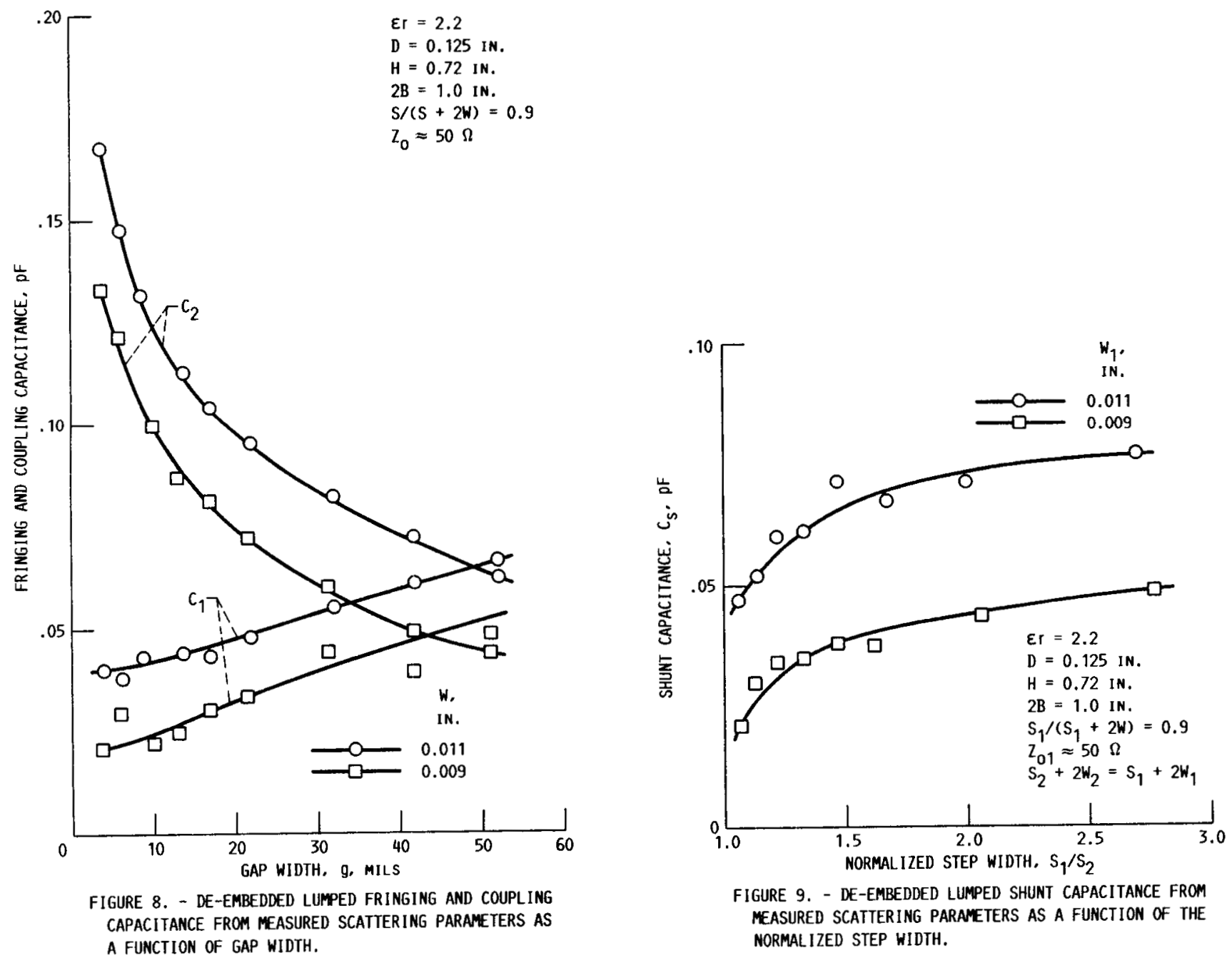

FIGURE 9. - DE-EMBEDDED LUMPED SHUNT CAPACITANCE FROM MEASURED SCATTERING PARAMETERS AS A FUNCTION OF THE NORMALIZED STEP WIDTH. 


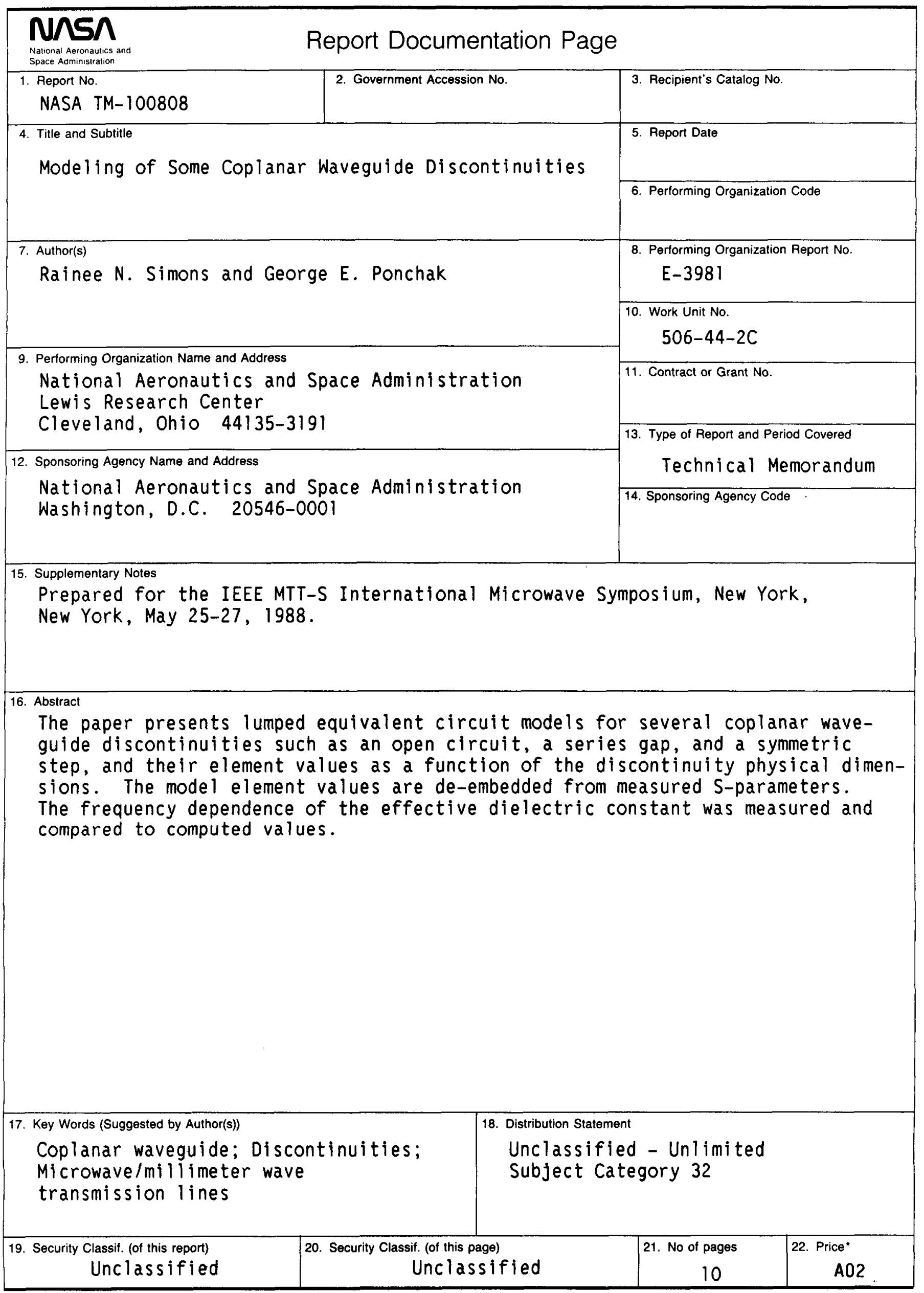

